\title{
Rituximab Treatment for PR3-ANCA-Positive Membranoproliferative Glomerulonephritis Associated with Adult-Onset Periodic Fever Syndrome
}

\author{
Yoshitomo Hamano ${ }^{a, b}$ Hiromichi Yoshizawa ${ }^{a}$ \\ Taro Sugase $^{\mathrm{a}}$ Takuya Miki $^{\mathrm{a}}$ Naoko Ohtani ${ }^{\mathrm{a}}$ \\ Shiho Hanawa ${ }^{a}$ Eri Takeshima $^{a}$ Yoshiyuki Morishita ${ }^{a}$ \\ Osamu Saito $^{a}$ Fumi Takemoto $^{a}$ Shigeaki Muto $^{a}$ \\ Wako Yumura ${ }^{c}$ Eiji Kusano ${ }^{a}$ \\ ${ }^{a}$ Division of Nephrology, Department of Internal Medicine, Jichi Medical \\ University Hospital, Shimotsuke, Tochigi, ' Department of Nephrology, Tokyo \\ Metropolitan Geriatric Hospital and Institute of Gerontology, Tokyo, and \\ 'Department of Nephrology, International University of Health and Welfare \\ Hospital, Nasushiobara, Tochigi, Japan
}

\section{Key Words}

Membranoproliferative glomerulonephritis · Periodic fever syndrome $\cdot$ Rituximab · PR3-ANCA

\begin{abstract}
We report the case of a 36-year-old Japanese woman with nephrotic syndrome due to membranoproliferative glomerulonephritis (MPGN) Type I diagnosed after a 5-year history of periodic fever syndrome (PFS). Hypocomplementemia and elevation of anti-proteinase 3 anti-neutrophil cytoplasmic autoantibody (PR3-ANCA) were observed. HIV, and hepatitis $B$ and $C$ serology were negative. Nephrotic syndrome and periodic fever did not respond to oral steroid and intravenous steroid pulse therapies combined with cyclosporine, dipyridamole, warfarin and losartan. We tried immunotherapy using rituximab, a human-mouse chimeric monoclonal antibody directed against the CD20 antigen on mature $B$ cells. This therapeutic approach led to improvement of renal function and remission of nephrotic syndrome and hypocomplementemia. However, it did not have a beneficial effect on periodic fever. Suspecting adult-onset hereditary PFS, we analyzed her genetic alteration
\end{abstract}


of MEFV and TNFRSF1A genes. A rare genotype in intron 6 of TNFRSF1A was revealed. The etiological relationship between periodic fever and MPGN is discussed. Rituximab is a hopeful choice of induction therapy for refractory MPGN.

\section{Introduction}

Membranoproliferative glomerulonephritis (MPGN) refers to an immune complex glomerulonephritis characterized by diffuse mesangial proliferation and interposition of mesangial cells into glomerular capillary walls, with double-contoured appearance of glomerular basement membranes [1]. MPGN is not a diagnostic label for one disease, but rather a description of a glomerular reaction to a variety of causes [1].

Periodic fever syndromes (PFS) are defined as diseases with recurrent episodes of systemic inflammation with spiking fever and spontaneous resolution [2]. They are now classified as autoinflammatory disorders involving dysregulations of innate immunity. Besides hereditary periodic fevers, the definition of PFS has been expanded to include other nongenetic disorders with similar clinical patterns including those of adult onset [2].

We describe a case with adult-onset periodic fever and MPGN, which was resistant to conventional steroid therapy. The effect of rituximab on this case was impressive: Although the nephrotic syndrome was remarkably ameliorated by rituximab treatment, the periodic fever was almost unchanged. We discuss the etiological relationship between MPGN and periodic fever.

\section{Case Report}

A 36-year-old Japanese woman was referred to a local hospital in August 2003 because of frequent asthmatic attacks, skin rash and periodic high-grade fever. Her medical history was childhood asthma. Despite repeated bacterial cultures, endoscopies, bone marrow examination and imaging studies including gallium scintigraphy and positron emission tomography, the cause of her fever could not be identified and antibiotics including isoniazid were ineffective. Her periodic fever did not improve after her asthma had ameliorated by combination therapy of weekly intravenous methylprednisolone, oral cyclosporine and intramuscular gold sodium thiomalate. No recurrent fever was noted in her family.

In November 2008, she presented with facial edema and gain of body weight (52 to $60 \mathrm{~kg}$ ), nephrotic-range proteinuria and hematuria, impaired renal function, hypocomplementemia and positivity of anti-proteinase 3 anti-neutrophil cytoplasmic autoantibody (PR3-ANCA, $46.0 \mathrm{U} / \mathrm{ml}$; normal value $<10 \mathrm{U} / \mathrm{ml}$ ). She was transferred to our hospital in February 2009 for definitive diagnosis and treatment.

The patient was pale, febrile $\left(38.7^{\circ} \mathrm{C}\right)$ and hypertensive $(176 / 100 \mathrm{~mm} \mathrm{Hg})$. She had normal heart and vesicular sounds. Edema of the eyelids was observed. Examinations for skin eruption, ulcer in the oral cavity, splenomegaly and lymphadenopathy were negative. She had neither joint deformity nor serositis.

Laboratory examinations, listed in table 1 revealed a white blood cell count of 4,900/ $\mu$ (with 3,800 neutrophils $/ \mu \mathrm{l}$ and 100 eosinophils $/ \mu \mathrm{l}$ ), a hemoglobin level of $6.4 \mathrm{~g} / \mathrm{dl}$, and a platelet count of $20.0 \times 10^{4} / \mu \mathrm{l}$. Biochemical investigations revealed a serum creatinine level of $1.71 \mathrm{mg} / \mathrm{dl}$ (151 $\mu \mathrm{mol} / \mathrm{l})$, a BUN level of $26 \mathrm{mg} / \mathrm{dl}(9.28 \mathrm{mmol} / \mathrm{l})$, a serum total protein level of $5.6 \mathrm{~g} / \mathrm{dl}$ and a 
serum albumin level of $2.8 \mathrm{~g} / \mathrm{dl}$. Lowered serum iron $(5 \mu \mathrm{g} / \mathrm{dl})$ and transferrin saturation (2.3\%) were also observed.

Urinalysis showed proteinuria (5.7 g/day; $6.1 \mathrm{~g} / \mathrm{g}$ creatinine) with dysmorphic hematuria ( $>30 / \mathrm{HPF}$ ). Anti-nuclear antibody titer was within normal range, and all of the following autoantibodies were negative: anti-ds DNA, anti-Sm, anti-SS-A, anti-SS-B, anti-cardiolipin (IgM and IgG class) and anti-GBM antibodies. Anti-streptolysin antibody and anti-streptokinase antibody were negative. 50\% hemolytic unit of complement was markedly decreased $(<11.0 \mathrm{U} / \mathrm{ml}$; normal range, 24.7-39.5 U/ml), as well as C3 (19 mg/dl; normal range, $86-160 \mathrm{mg} / \mathrm{dl})$ and C4 (10 mg/dl; normal range, $17-45 \mathrm{mg} / \mathrm{dl})$. Rheumatoid factor (1-160; normal value, <1-40) and immune complex (C1q binding assay, $29.5 \mu \mathrm{g} / \mathrm{ml}$; normal value, $<2.9 \mu \mathrm{g} / \mathrm{ml}$ ) were detected. Although IgG-type cryoglobulinemia was detected, it was less than $1 \%$ in cryocrit. Viral serology (hepatitis B, hepatitis $\mathrm{C}$ and human immunodeficiency virus) was negative. Serum levels of IgG, IgG4, IgA, IgD and IgE were within normal range but IgM was increased (414 mg/dl; normal range, 46-260 mg/dl). Serum and urinary protein immunoelectrophoresis did not detect M-proteins. Serum PR3-ANCA level was elevated ( $44.1 \mathrm{U} / \mathrm{ml}$; normal value, $<3.5 \mathrm{U} / \mathrm{ml}$ ) but MPO-ANCA level was within normal range. The QuantiFERON-TBTM Gold test was negative. The patient did not fulfill American College of Rheumatology criteria for systemic lupus erythematosus, granulomatosis with polyangiitis (Wegener's), and Churg-Strauss syndrome.

Percutaneous renal biopsy was performed on February 3, 2009. Diffuse mesangial and endocapillary proliferative lesions, lobulation of the glomerular tuft and double contour of glomerular basement membrane were observed (fig. $1 \mathrm{~A}$ and B), with cellular or fibrocellular crescents in over $50 \%$ of glomeruli (fig. 1B). Immunofluorescence studies (fig. 1C) revealed mesangial and capillary wall staining of C3c and C1q. In contrast, marginal segmental staining of IgG, IgA and IgM (not shown) was observed. Mesangial and subendothelial (fig. 1D) electron-dense deposits were observed in electron microscopy.

Although C1q was stained in glomerular capillary loop, immunoglobulins were minimally stained. These findings were consistent with histopathological characteristics of MPGN Type I [1] rather than those of lupus nephritis or secondary MPGN by cryoglobulinemia. Serum cryoglobulin turned negative in February 2010, irrespective of the state of nephrotic syndrome.

Her fever was periodic (fever spike of $>39^{\circ} \mathrm{C}$ every 10 days to 2 weeks), associated with arthralgia and urticaria-like skin rash. Her skin rash lasted for $<8 \mathrm{~h}$ and no residual effect was observed. She did not have chest pain or abdominal pain with fever. Her fever synchronized with elevation of C-reactive protein (dashed line, fig. 2E) and neutrophilia (not shown). Peripheral blood level of proinflammatory cytokines was elevated: TNF- $\alpha, 21.2 \mathrm{pg} / \mathrm{ml}$ (reference range, $0.6-2.8 \mathrm{pg} / \mathrm{ml}$ ); IL-1 $\beta, 15 \mathrm{pg} / \mathrm{ml}$ (reference value, $<10 \mathrm{pg} / \mathrm{ml}$ ); and IL-6, $97.6 \mathrm{pg} / \mathrm{ml}$ (reference value, $<0.4 \mathrm{pg} / \mathrm{ml}$ ). These observations led us to suspect hereditary PFS. However, she did not have any disease-specific features such as prolonged fever pattern, cold-induced fever, deafness, deforming arthropathy, elevated IgD, or monoclonal gammopathy. Two diseases, familial Mediterranean fever (FMF) and TNF receptor-associated periodic syndrome (TRAPS), are described as possibly being of adult onset among hereditary PFS [2]. We analyzed the patient's genes for these two diseases. As for FMF, no mutation in exons 1, 2, 3 and 10 of the $M E F V$ gene was detected (Dr. Kiyoshi Migita, personal communication). The patient had a rare genotype $(\mathrm{c} .625+10 \mathrm{G} / \mathrm{G})$ in intron 6 of the TNF receptor gene TNFRSF1A, but no mutation in exons 2, 3, 4, 6 and 7 (Dr. Hiroaki Ida, personal communication). The pathogenic role of this genotype is unknown. Her disease was diagnosed as MPGN Type I associated with unclassified adult-onset PFS.

She was treated with 3 doses of intravenous methylprednisolone ( $500 \mathrm{mg} /$ day) followed by oral methylprednisolone (40 mg/day) (fig. 2). Although steroid therapy partially improved several parameters, nephrotic syndrome and renal function worsened as steroids were tapered (fig. 2A-C). High-dose steroid therapy did not substantially ameliorate her periodic fever. Colchicine, effective for FMF [2], did not improve her fever (fig. 2E). Under these backgrounds, rituximab treatment was proposed.

For the use of rituximab the patient's written informed consent and approval of the Bioethics Committee of Jichi Medical University were obtained. Rituximab $\left(375 \mathrm{mg} / \mathrm{m}^{2}\right)$ was given once a week for 4 consecutive weeks. Peripheral blood CD19+ B cells were depleted (fig. $2 F$, middle and right columns). Proteinuria, serum albumin, renal function and hypocomplementemia rapidly ameliorated 
to baseline (fig. 2A-C). Despite remarkable improvement of nephrotic syndrome and hypocomplementemia, her periodic fever was unchanged after rituximab treatment (fig. 2E). Proteinuria decreased to $<1 \mathrm{~g} /$ day and complement levels were within normal range, but her fever was unaltered until 1 year after administration of rituximab.

\section{Discussion}

We reported a case of MPGN Type I with periodic fever and systemic inflammatory symptoms (shivers, joint pain, and skin rash) common in PFS. To date, over 10 PFS have been reported. They include FMF, TRAPS, Schnitzler's syndrome, mevalonate kinase deficiency, the cryopyrin-associated periodic syndromes, deficiency of the interleukin (IL)-1-receptor antagonist, pyogenic arthritis, pyoderma gangrenosum and acne syndrome, periodic fever, aphthous stomatitis, pharyngitis and cervical adenitis syndrome and Blau syndrome [2]. Three of these diseases can be of adult onset [2]. Because the characteristics of Schnitzler's syndrome (monoclonal IgM gammopathy and chronic urticarial rash) were not found, the candidate diagnoses were FMF and TRAPS. The patient did not have any obvious genetic alterations in $M E F V$ and TNFRSF1A. However, her disease may still be diagnosed as one of these syndromes, since incomplete FMF cases and TRAPS-like cases without TNFRSF1A mutation have been reported [3, 4]. Because new genetic syndromes of periodic fever are still discovered at a rate of about 1 every 2 years [2], a new disease is another possible diagnosis.

MPGN encompasses both idiopathic and secondary forms associated with infections, cryoglobulinemia, autoimmune diseases, neoplasms, and thrombotic microangiopathies [1]. To review the literature, PubMed and Web of Science databases were searched combining the terms MPGN and periodic fever. To date, 2 cases of MPGN with PFS (FMF) were reported [5]. One important aspect in the pathogenesis of MPGN is abnormalities in humoral immunity, especially those against the complement system. They are represented by the production of immune complexes and autoantibodies against proteins in the complement system such as C3 convertase or C1q [1]. Unfortunately, C3 nephritic factor was not examined, but increased serum immune complex measured by solid phase $\mathrm{C} 1 \mathrm{q}$ binding assay (table 2) and predominant deposition of C1q in glomeruli (fig. 1C) suggests the involvement of autoantibody against C1q. We hypothesize that there is an etiologic relationship between periodic fever (autoinflammation) and MPGN in this case.

During inflammation, the combination of the inflammatory mediators released from activated antigen-presenting cells and the increased expression of co-stimulatory molecules can have effects on priming lymphocytes [6]. This can be the basis for a persistent hyperproduction of antibodies and the formation of immune complexes preferentially localizing to the subendothelial space of glomeruli. Autoreactive lymphocytes also can be activated in these circumstances, particularly if tissue destruction by the inflammation leads to an increase in the availability of the self-antigen [6]. Activated innate immunity results in the formation of protein complexes termed inflammasomes. Shaw et al. [7] described that the role of inflammasome in some autoimmune diseases is probable because inflammasome products such as IL- $1 \beta$ play a role in shaping adaptive immunity through activation of T cells and B cells. This may result in the production of (auto)antibodies possibly against 
complement factors or proteinases. Regarding MPGN as the dysregulation of humoral immunity secondary to autoinflammation, it makes sense that rituximab created complete remission of MPGN but scarcely had an effect on periodic fever. A similar clinical course was reported in a case of acquired periodic fever, in which depletion of B cells by rituximab resulted in a dramatic reduction of immunoglobulin but did not have a beneficial effect on systemic inflammatory symptoms [8].

PR3-ANCA is closely associated with systemic vasculitis, especially granulomatosis with polyangiitis (Wegener's). The pathogenic roles and diagnostic values of ANCA are established [9]. However, in several reports ANCA is also related to other inflammatory diseases, drug administration and infection [9]. PR3-ANCA in this case did not correlate with renal function or urinary findings (fig. 2A-D). This suggests that in our case the production of ANCA reflects neutrophil-activating conditions due to inflammation, not a state specific to vasculitis [10]. The early decrease of ANCA may have occurred due to immunosuppression by methylprednisolone. After administration of rituximab, the level of PR3-ANCA slightly decreased from $4.7 \mathrm{U} / \mathrm{ml}$ to $3.7 \mathrm{U} / \mathrm{ml}$.

Although the primary indication for rituximab is B-cell neoplasm, encouraging results have been observed in autoimmune diseases such as lupus nephritis, systemic vasculitis, and glomerular diseases [11]. Rituximab therapy has been applied for MPGNs related to HCV [12], cryoglobulinemia [11], post transplantation [13], and B-cell tumors [14]. Clinical studies of rituximab in glomerulonephritis have been performed for lupus nephritis, vasculitis and membranous nephropathy [15], but rituximab is regarded as a future therapeutic strategy for MPGN [1]. Our case suggests the future use of rituximab as induction therapy in MPGN refractory to conventional therapies.

In conclusion, we reported the case of an adult with periodic fever complicated by nephrotic syndrome 5 years after the onset of fever. An elevation of PR3-ANCA was also observed. By renal biopsy, the renal disease was diagnosed as MPGN Type I. Rituximab treatment led to complete remission of nephrotic syndrome but had virtually no effect on periodic fever. This unique pattern of effect implies that rituximab only improved immune dysregulation (MPGN) but did not improve its etiological background (PFS or autoinflammation). Rituximab is a hopeful drug for the treatment of refractory MPGN.

\section{Acknowledgements}

We thank Dr. Hiroaki Ida (Kurume University Hospital) and Dr. Kiyoshi Migita (National Hospital Organization Nagasaki Medical Center) for their genetic analyses. We thank Dr. C.H. Asakawa, Dr. J. Chinda, Dr. Y. Chinzei, Dr. H. Inoue, Dr. M. Inoue, Dr. K. Kadowaki, Dr. T. Masuda, Dr. T. Masuko, Dr. K. Nishino, Dr. M. Saito, Dr. T. Sasaki, Dr. Y. Takeda, Dr. M. Taki, Dr. X. Cine, Dr. S. Yamazaki, and Dr. C. Yokozuka for their assistance.

\section{Disclosure Statement}

The authors have no conflicts of interest to disclose. 
Table 1. Laboratory data on admission

\begin{tabular}{|c|c|c|}
\hline Parameters & Values & Normal ranges \\
\hline \multicolumn{3}{|l|}{ Blood count } \\
\hline White blood cells & $4,900 / \mu \mathrm{l}$ & $3,500-9,100$ \\
\hline Eosinophils & $2.4 \%$ & $0-5.8$ \\
\hline Red blood cells & $246 \times 10^{4} / \mu \mathrm{l}$ & $376-500$ \\
\hline Hemoglobin & $6.4 \mathrm{~g} / \mathrm{dl}$ & $11.3-15.2$ \\
\hline Platelets & $20 \times 10^{4} / \mu \mathrm{l}$ & $13-36.9$ \\
\hline \multicolumn{3}{|l|}{ Blood chemistry } \\
\hline Total protein & $5.6 \mathrm{~g} / \mathrm{dl}$ & $6.9-8.4$ \\
\hline Albumin & $2.8 \mathrm{~g} / \mathrm{dl}$ & $3.9-5.1$ \\
\hline Total cholesterol & $168 \mathrm{mg} / \mathrm{dl}$ & $127-258$ \\
\hline Blood urea nitrogen & $26 \mathrm{mg} / \mathrm{dl}$ & $8-20$ \\
\hline Creatinine & $1.71 \mathrm{mg} / \mathrm{dl}$ & $0.38-0.90$ \\
\hline Uric acid & $7.9 \mathrm{mg} / \mathrm{dl}$ & $2.3-5.9$ \\
\hline Sodium & $146 \mathrm{mmol} / \mathrm{l}$ & $136-148$ \\
\hline Potassium & $3.3 \mathrm{mmol} / \mathrm{l}$ & $3.6-5.0$ \\
\hline Chloride & $105 \mathrm{mmol} / \mathrm{l}$ & $96-108$ \\
\hline Calcium & $7.7 \mathrm{mg} / \mathrm{dl}$ & $8.2-9.6$ \\
\hline Inorganic phosphate & $4.1 \mathrm{mg} / \mathrm{dl}$ & $2.4-4.6$ \\
\hline Iron & $5 \mu \mathrm{g} / \mathrm{dl}$ & $53-158$ \\
\hline $\begin{array}{l}\text { Unsaturated iron binding } \\
\text { capacity }\end{array}$ & $208 \mu \mathrm{g} / \mathrm{dl}$ & $142-341$ \\
\hline Ferritin & $39.9 \mathrm{ng} / \mathrm{ml}$ & $3.0-59.2$ \\
\hline C-reactive protein & $1.43 \mathrm{mg} / \mathrm{dl}$ & $<0.06$ \\
\hline \multicolumn{3}{|l|}{ Urinalysis } \\
\hline Gravity & 1.015 & $1.005-1.035$ \\
\hline $\mathrm{pH}$ & 7.5 & $5.0-8.0$ \\
\hline Protein & +++ & - \\
\hline Glucose & - & - \\
\hline Occult blood reaction & +++ & - \\
\hline \multicolumn{3}{|l|}{ Urine sediment } \\
\hline Erythrocytes & \multicolumn{2}{|l|}{ 30/high-power field } \\
\hline Hyaline casts & \multicolumn{2}{|l|}{ 1-2/whole field } \\
\hline Granular casts & \multicolumn{2}{|l|}{$1-2 /$ whole field } \\
\hline \multirow[t]{2}{*}{ Urinary protein } & $5.6 \mathrm{~g} /$ day, & $<0.03 \mathrm{~g} / \mathrm{l}$ \\
\hline & \multicolumn{2}{|c|}{$7.2 \mathrm{~g} / 1 \mathrm{~g}$ creatinine } \\
\hline
\end{tabular}


Table 2. Immunological findings and serum cytokine levels

\begin{tabular}{|c|c|c|}
\hline Parameters & Values & Normal ranges \\
\hline IgG & $1,072 \mathrm{mg} / \mathrm{dl}$ & $870-1,700$ \\
\hline IgA & $150 \mathrm{mg} / \mathrm{dl}$ & $110-410$ \\
\hline IgM & $414 \mathrm{mg} / \mathrm{dl}$ & $46-260$ \\
\hline IgE & $22 \mathrm{U} / \mathrm{ml}$ & $<216$ \\
\hline IgD & $2 \mathrm{mg} / \mathrm{dl}$ & $2-12$ \\
\hline IgG4 & $16.6 \mathrm{mg} / \mathrm{dl}$ & $4.8-150$ \\
\hline M-protein & Negative & Negative \\
\hline ASO & $<20 \mathrm{U} / \mathrm{ml}$ & $<187$ \\
\hline ASK & $\times 80$ & $\times 1,280$ \\
\hline Rheumatoid factor & $\times 160$ & $\times 40$ \\
\hline Anti-nuclear antibody & Negative & Negative \\
\hline Anti-ds DNA antibody & Negative & Negative \\
\hline Anti-Sm antibody & Negative & Negative \\
\hline Anti-cardiolipin antibody (IgM-class) & Negative & Negative \\
\hline Anti-cardiolipin antibody (IgG-class) & Negative & Negative \\
\hline Anti-SS-A antibody & Negative & Negative \\
\hline Anti-SS-B antibody & Negative & Negative \\
\hline Anti-GBM antibody & Negative & Negative \\
\hline Cryoglobulin (IgG-class) & Positive & Negative \\
\hline Cryocrit & $<1 \%$ & 0 \\
\hline MPO-ANCA & $<1.3 \mathrm{U} / \mathrm{ml}$ & $<9.0$ \\
\hline PR3-ANCA & $44.1 \mathrm{U} / \mathrm{ml}$ & $<3.5$ \\
\hline Immune complex & $29.5 \mu \mathrm{g} / \mathrm{ml}$ & $<2.9$ \\
\hline $\mathrm{C} 3$ & $19 \mathrm{mg} / \mathrm{dl}$ & $86-160$ \\
\hline $\mathrm{C} 4$ & $10 \mathrm{mg} / \mathrm{dl}$ & $17-45$ \\
\hline CH50 & $<11.0 \mathrm{U} / \mathrm{ml}$ & $24.7-39.5$ \\
\hline Hepatitis B antigen & Negative & Negative \\
\hline Hepatitis C antibody & Negative & Negative \\
\hline Serological tests for syphilis & Negative & Negative \\
\hline HIV antibody & Negative & Negative \\
\hline Blood culture & Negative & Negative \\
\hline QuantiFERON-TB test & Negative & Negative \\
\hline TNF- $\alpha$ & $21.2 \mathrm{pg} / \mathrm{ml}$ & $0.6-2.8$ \\
\hline IL-1 $\beta$ & $15 \mathrm{pg} / \mathrm{ml}$ & $<10$ \\
\hline IL-6 & $97.6 \mathrm{pg} / \mathrm{ml}$ & $<0.4$ \\
\hline
\end{tabular}



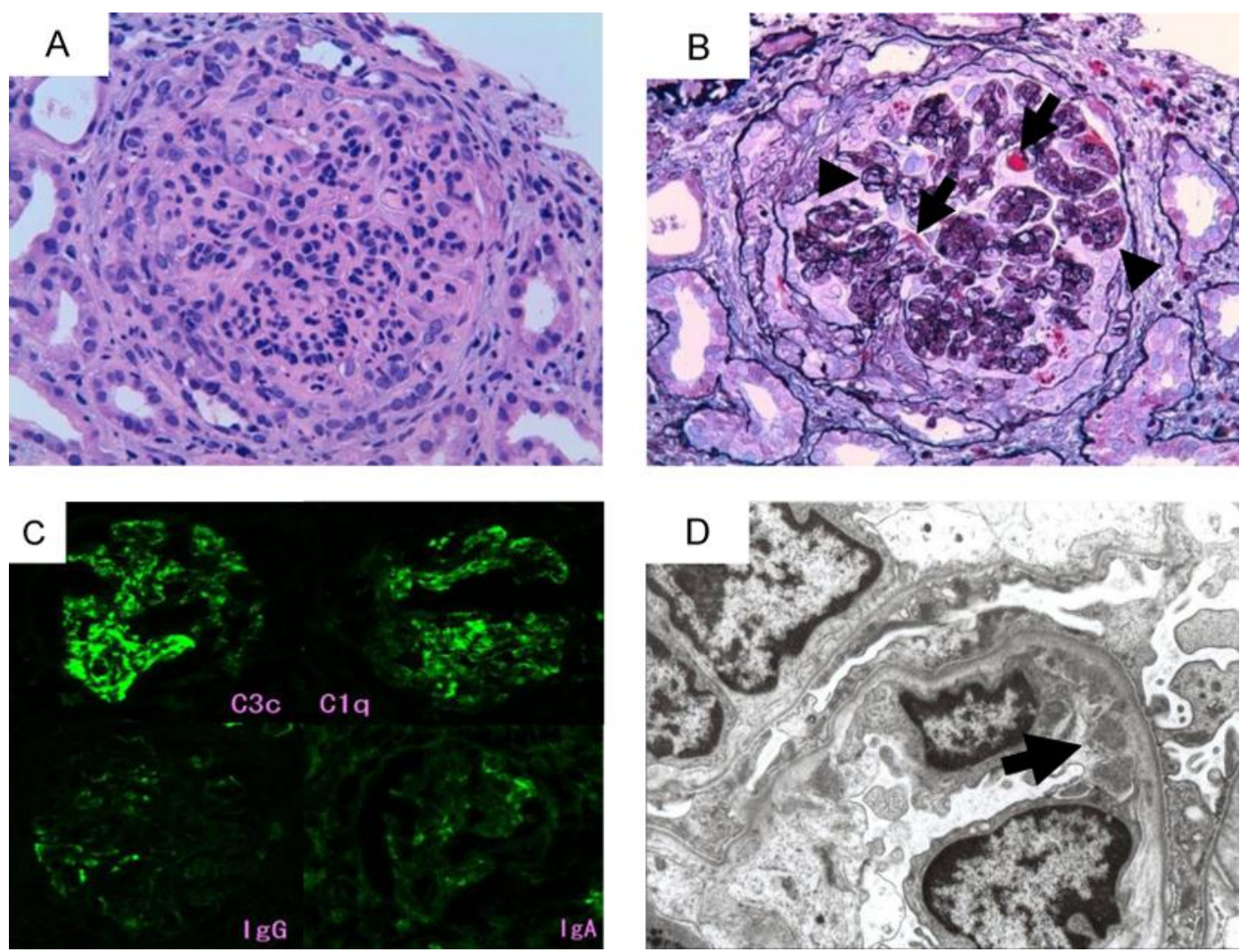

Fig. 1. Renal biopsy findings. A Light microscopy image showed endocapillary and mesangial proliferation (H\&E stain, original magnification $\times 200$ ). B A glomerulus showed lobulation of glomerular tuft, eosinophilic subendothelial deposits (arrows), double contour of the glomerular basement membrane (arrowheads), and cellular crescent formation (PAM-Masson stain, original magnification $\times 200$ ). C Immunofluorescence micrographs showed positive staining for C3c and C1q in mesangium and periphery. However, stainings of IgG and IgA were scarce. D Subendothelial electron dense deposits (arrow) were found in electron micrograph. 


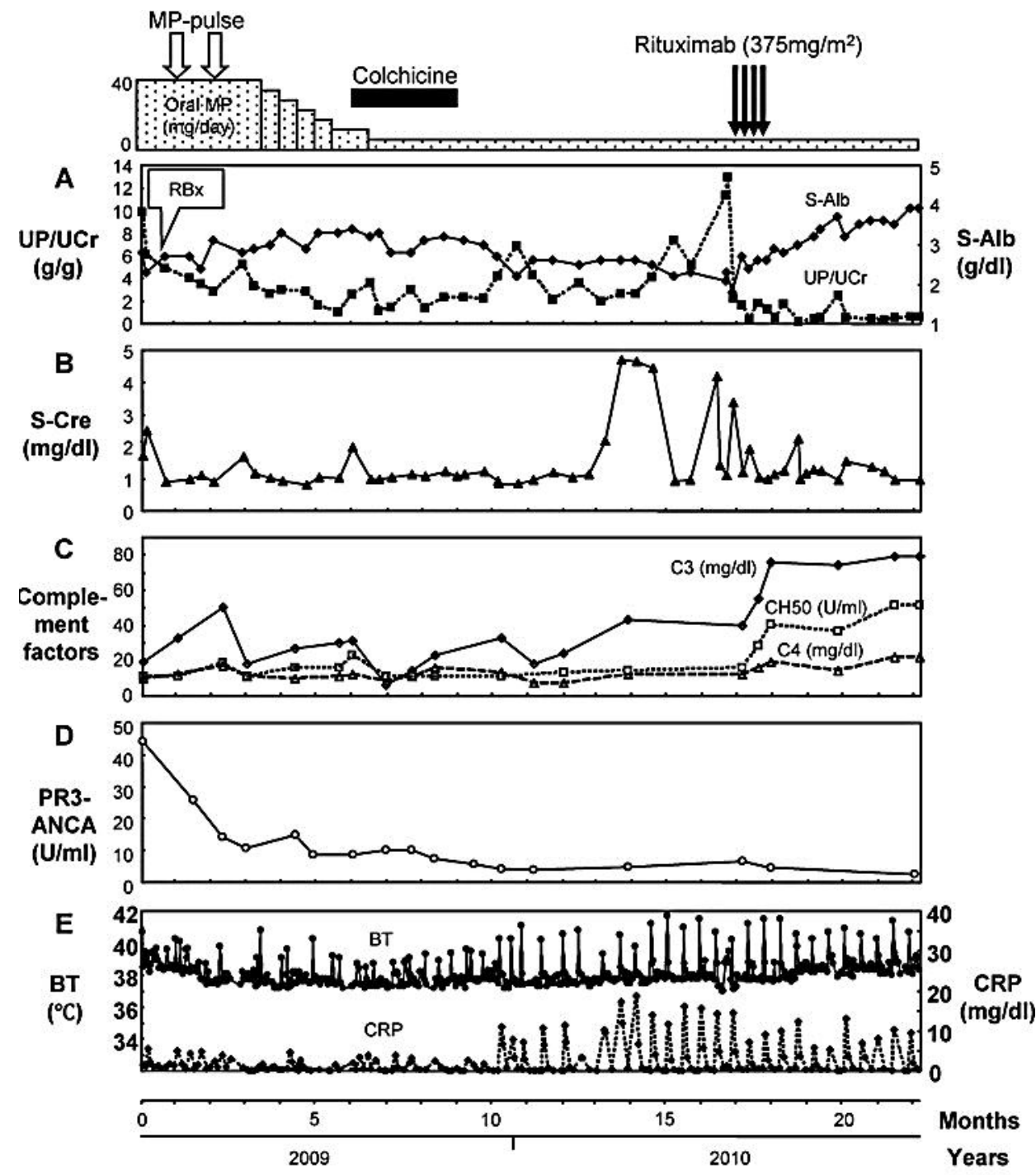

$\mathbf{F}$

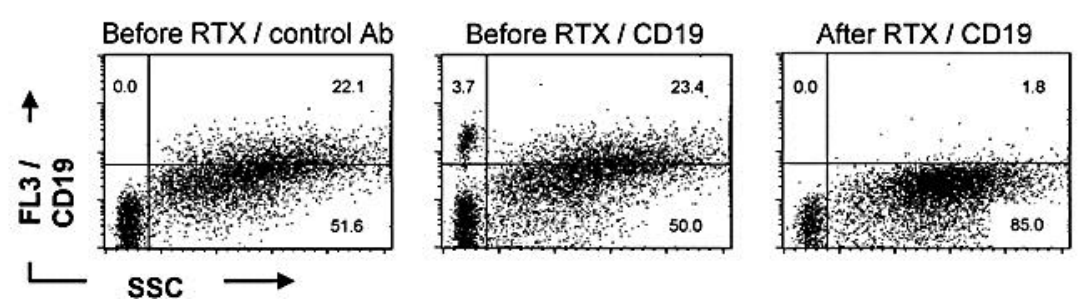

Fig. 2. A-E Therapies and time course of clinical parameters. Therapies are shown at the top. The dose of colchicine was $0.5-2 \mathrm{mg} /$ day. $\mathrm{MP}=$ Methylprednisolone; UP = urinary protein; $\mathrm{UCr}=$ urinary creatinine; $\mathrm{RBx}=$ renal biopsy; S-Alb = serum albumin; S-Cre = serum creatinine; $\mathrm{BT}=$ body temperature; $\mathrm{CRP}=\mathrm{C}$-reactive protein. $\mathbf{F}$ Peripheral blood flow cytometry profiles.

CD19+SSClow B cells (upper left quadrant of middle column) were substantially depleted by administration of rituximab (right column). RTX = Rituximab; $\mathrm{Ab}=$ antibody; SSC = side scatter. 


\section{References}

1 Alchi B, Jayne D: Membranoproliferative glomerulonephritis. Pediatr Nephrol 2010;25:1409-1418.

12 Lachmann HJ: Clinical immunology review series: an approach to the patient with a periodic fever syndrome. Clin Exp Immunol 2011;165:301-309.

-3 Livneh A, Langevitz P, Zemer D, Zaks N, Kees S, Lidar T, Migdal A, Padeh S, Pras M: Criteria for the diagnosis of familial Mediterranean fever. Arthritis Rheum 1997;40:1879-1885.

4 Borghini S, Fiore M, Di Duca M, Caroli F, Finetti M, Santamaria G, Ferlito F, Bua F, Picco P, Obici L, Martini A, Gattorno M, Ceccherini I: Candidate genes in patients with autoinflammatory syndrome resembling tumor necrosis factor receptor-associated periodic syndrome without mutations in the TNFRSF1A gene. J Rheumatol 2011;38:1378-1384.

5 Akpolat T, Akpolat I, Karagoz F, Yilmaz E, Kandemir B, Ozen S: Familial Mediterranean fever and glomerulonephritis and review of the literature. Rheumatol Int 2004;24:43-45.

6 Murphy K, Travers P, Walport M: Autoimmunity and transplantation; in Murphy K (ed): Janeway's Immunobiology, ed 7. New York, Garland Science, 2008, pp 599-654.

7 Shaw PJ, McDermott MF, Kanneganti TD: Inflammasomes and autoimmunity. Trends Mol Med 2011;17:57-64.

8 Dinarello CA: Interleukin-1 in the pathogenesis and treatment of inflammatory diseases. Blood 2011;117:3720-3732.

9 Hoffman HM, Simon A: Recurrent febrile syndromes: what a rheumatologist needs to know. Nat Rev Rheumatol 2009;5:249-256.

10 Knight A, Ekbom A, Brandt L, Askling J: What is the significance in routine care of c-ANCA/PR3-ANCA in the absence of systemic vasculitis? A case series. Clin Exp Rheumatol 2008;26:S53-S56.

11 Gurcan HM, Keskin DB, Stern JN, Nitzberg MA, Shekhani H, Ahmed AR: A review of the current use of rituximab in autoimmune diseases. Int Immunopharmacol 2009;9:10-25.

12 Bestard O, Cruzado JM, Ercilla G, Goma M, Torras J, Seron D, Rama I, Ibernon M, Vinas O, Carrera M, Grinyo JM: Rituximab induces regression of hepatitis $C$ virus-related membranoproliferative glomerulonephritis in a renal allograft. Nephrol Dial Transplant 2006;21:2320-2324.

-13 Damodar A, Mustafa R, Bhatnagar J, Panesar M, Gundroo A, Zachariah M, Blessios G, Tornatore K, Weber-Shrikant E, Venuto R: Use of anti-CD20 antibody in the treatment of post-transplant glomerulonephritis. Clin Transplant 2011;25:375-379.

14 Bartel C, Obermüller N, Rummel MJ, Geiger H, Hauser IA: Remission of a B cell CLL-associated membranoproliferative glomerulonephritis Type I with rituximab and bendamustine. Clin Nephrol 2008;69:285-289.

15 Jayne D: Role of rituximab therapy in glomerulonephritis. J Am Soc Nephrol 2010;21:14-17. 